\title{
Role of physiotherapy in palliative care
}

\author{
MD. Sheeba Kauser ${ }^{1, *}$, Shahul S.A ${ }^{2}$ \\ ${ }^{1}$ Physiotherapist, ${ }^{2}$ Resident, ${ }^{1}$ Dept. of Physiotherapy, ${ }^{2}$ Dept. of Orthopaedics, Apollo Hospital, Nellore, Andhra Pradesh, India
}

*Corresponding Author:

Email: sheebaishaq.doc@gmail.com

The growing cases of cancer survivors almost 1 in ever 20 adults and nearly 1 in 5 of all people over age 65 in the U.S have survived cancer, ${ }^{1}$ with the help of services such as lymphedema therapy, hospice, and palliative care. Studies show that patients with the advanced care who received early palliative care reported better quality of life and have extension of span of years in life, where also the palliative care have provided to add life to their years. ${ }^{2}$

Larger population studies have identified a strong association between lower levels of physical activity and higher cancer mortality. Walking or cycling an average of 30 minutes per day has been associated with a $34 \%$ lower rate of cancer death and 33\% improved cancer survival. $^{3}$

Increasing numbers of studies are indicating that physical activity can reduce the incidence of cancer. World Health Organization recommends that 150 minutes of moderate intensity aerobic physical activity a week can reduce the risk of breast and colon cancers. ${ }^{4}$

Palliative care is an very good approach that improves the quality of life of patients and their families facing the problem associated with the lifethreatening illness, through the prevention and relief of suffering with early detection and authentic and impeccable assessment and treatment aiming for physical, psychosocial and spiritual. $^{5}$

Physiotherapy is an integral important part of palliative care. It aims to improve survivor's quality of life where mainly aims for functional ability and independence or gain relief from distressing symptoms. ${ }^{6}$ Palliative care is a rapidly expanding with involvement of physiotherapists. Implementation of a massage, relaxation therapy, exercise therapy program, respiratory rehabilitation, modified manual lymphedema a treatment has been assessed in the studies. ${ }^{7,12}$

Authors conclude that physiotherapy intervention helps to maximize patients functional potential. Moreover high levels of satisfaction with the physiotherapy intervention were observed.

In past, rehabilitation was perceived as treatment which was to lead full recovery of a patient. This concept of rehabilitation may seem paradoxical in palliative care, especially for patients with an advanced illness who are approaching death. At present the purpose of rehabilitation is to improve the quality of life as discussed above not only "increasing years to the life but also to add life to the years." As that the patient would feel more comfortable on getting functional independency he would feel a hope of recovery and would have positive approach to the treatment. ${ }^{13}$

Rehabilitation plays an important role significantly in treating the survivor. Elise and Fulton have throwed light on the importance of physiotherapy in palliative care optimizing patients level of physical function and take into consideration the inter lin between the physical, psychological, social and vocational domains of functions. ${ }^{14}$

Where as in the palliative care the goals of physiotherapist should be shortly achievable and should be realistic, the presence of physiotherapist should be flexible adapting to any approach to treat the patient with the demand and degree of the disease of the survivor. Studies have indicated a relationship between higher physical activity levels and lower mortality in cancer survivors. A recent meta-analysis reported that, post-diagnosis, physical activity reduced breast cancer deaths by $34 \%$, all causes mortality by $41 \%$ and disease recurrence by $24 \% .^{15}$

Studies also indicate the volume of exercise necessary to bring benefits. The Nurses health study reported 50\% fewer cancer recurrences in women who exercised more than three hours per week. Among people who have had colo-rectal cancer, a study found a $50 \%$ lower rate of recurrence and related death in those who exercised more than six hours per week. ${ }^{16}$

People think cancer care and palliative care are sequentially similar but where as they are optimally concurrent. Early palliative surely would have greater impact on the patient for having quality life expectancy. Definitely enough and good studies have been quoted for the importance of physiotherapist in the palliative care, cancer being a umbrella term with many extensions of disease and its rising demands physical therapist has their own demand in the fight for the disease.

Message by the Authors: After a descriptive editorial this article which describes the importance of physical therapist in the field of palliative care treating an dreading and devasting disease we hope to convey the importance of physiotherapist for quality of life with functional independency......

Lets pledge out that with a team work of physiotherapists and (occupational and oncologists and oncosurgeons and with the persons needed) lets hope for the better life adding hope to the "cancer survivor". 
Lets hope........in coming years will shall strive

"Let cancer just be an zodaic sign not a breath taking disease"

\section{References}

1. Belluck, P. (2011, March 10). Number of cancer survivors rise by $20 \%$ in 6 years. Retrieved May 12 , 2011, from http://www.nytimes.com/2011/03/11/health/11 cance r.html

2. Hobson, K. (2010, August 18). Study: Advanced cancer patients receiving early palliative care live longer. Retrieved May 12, 2011, fromhttp://blogs.wsj.com/health/2010/08/18/studyadvanced-cancer-patients-receiving-early-palliative-carelived-longer/.

3. Orsini N, Mantzoros C S et al. Association of physical activity with cancer incidence,mortality, and survival: a population based study of men. British Journal of Cancer. 2008 98:1864-1869.

4. Global Recommendations on Physical Activity for Health, released by the World Health Organization in 2011.

http://www.who.int/dietphysicalactivity/factsheet_recom mendations/en/index.html.

5. WHO (World Health Organization). Cancer Pain Relief and Palliative Care: Report of a WHO Expert Committee. Technical Report Series, no.804. Geneva: World Health Organization 1990.

6. The Association of Chartered Physiotherapists in Oncology and Palliative Care (ACPOPC). Guidelines for Good Practice1993.

7. English A. Physiotherapy Management of Breathlessness in Palliative Care. Adv. Pall. Med. 2008;2:43-46.

8. Grzybek M., Mularczyk A., Ostrowski A.K., Krajnik M. The influence of rehabilitation (kinesiotherapy) on the quality of life of cancer patients provided with palliative care. Adv. Pall. Med. 2007;2:53-57.

9. Scialla S., Cole R., Scialla T., Bednarz L. et al. Rehabilitation for elderly patients with cancer asthenia: making a transition to palliative care. Pall. Med. 2000;14:121-127.

10. Montagnini M., Lodhi M., Born W. The utilization of physical therapy in palliative care unit. J. Pall. Med. 2003;1:11-17.

11. Crevenna R., Schmidinger M., Keilani M., Nuhr M. et al. Aerobic exercise for a patient suffering from metastatic bone disease. Supp. Care Cancer 2003, 11:120-122.

12. Mackey K., Sparling J.W. Experiences of Older Women With Cancer Receiving Hospice Care: Significance for Physical Therapy. Phys. Therapy 2000;5:459-468.

13. Tookman A.J., Hopkins K., Scharpen-von-Heussen K. Rehabilitation in palliative medicine. In: Textbook of Palliative Medicine, Third Edition. Doyle D., Hanks G., Cherny N.I., Calman K. Oxford University Press, Oxford 2004:1021-1032.

14. Fulton C.L., Else R. Rehabilitation in palliative care. In: Textbook of Palliative Medicine, Second Edition. Doyle D., Hanks G., MacDonald N. Oxford University Press, Oxford 1998:816-828.

15. Ibrahim EM, Al-Homaidh A. Physical activity and survival after breast cancer diagnosis: meta-analysis of published studies. Med Oncol. 2010 Apr 22.
16. Holmes, MD, Chen WY et al. Physical activity and survival after breast cancer diagnosis. JAMA 2005 293:2479-2486. 